\title{
Molecular and clinical analyses of the gene encoding the collagen-binding adhesin of Streptococcus mutans
}

\begin{abstract}
Correspondence
Kazuhiko Nakano

nakano@dent.osaka-u.ac.jp
\end{abstract}

Received 25 October 2008

Accepted 3 December 2008

\author{
Ryota Nomura, ${ }^{1}$ Kazuhiko Nakano, ${ }^{1}$ Naho Taniguchi, ${ }^{1}$ \\ Jinthana Lapirattanakul, ${ }^{1}$ Hirotoshi Nemoto, ${ }^{1}$ Lisa Grönroos, ${ }^{2}$ \\ Satu Alaluusua ${ }^{2,3}$ and Takashi Ooshima ${ }^{1}$
${ }^{1}$ Department of Pediatric Dentistry, Osaka University Graduate School of Dentistry, Suita, Osaka, Japan
${ }^{2}$ Department of Oral and Maxillofacial Diseases, Helsinki University Central Hospital, Helsinki, Finland
${ }^{3}$ Department of Pediatric and Preventive Dentistry, Institute of Dentistry, University of Helsinki, Helsinki, Finland

\begin{abstract}
Streptococcus mutans is a known pathogen of dental caries and its major cell surface antigens have been widely investigated. Recently, an approximately $120 \mathrm{kDa} \mathrm{Cnm}$ protein with binding properties to type I collagen was identified, and its encoding gene ( $\mathrm{cnm}$ ) cloned and sequenced. In the present study, we sequenced $\mathrm{cnm}$ from 47 different clinical S. mutans strains and found that the nucleotide alignment of the collagen-binding domain was well conserved. We devised a PCR method for identifying the $\mathrm{cnm}$ gene, examined the prevalence of $\mathrm{cnm}$-positive $S$. mutans strains in various mother-child groups, and assessed the significance of such strains for transmission and dental caries. The detection rate of $\mathrm{cnm}$-positive strains was significantly lower in strains isolated from Japanese children in the 2000 s (8.0\%) as compared to those isolated in the 1980 s $(15.8 \%)(P<0.05)$. Furthermore, the presence of $S$. mutans possessing $\mathrm{cnm}$ in salivary specimens collected from 55 S. mutans-positive mother-child pairs was 40 and $32.7 \%$ in the mothers and children, respectively. The frequency of $\mathrm{cnm}$-positive children whose mothers were also positive was $72 \%$, which was significantly higher than that of $c n m$-positive children with negative mothers $(P<0.0001$, odds ratio 17.5). In addition, clinical parameters indicating dental caries were significantly increased in children with $\mathrm{cnm}$-positive S. mutans in saliva $(n=13)$, as compared to those with $c n m$-negative $S$. mutans $(n=15)$ and $S$. mutans-negative children $(n=20)(P<0.01)$. These results indicate that $\mathrm{cnm}$-positive $S$. mutans strains are closely correlated with dental caries, while vertical transmission in $\mathrm{cnm}$-positive mother-child pairs was also demonstrated.
\end{abstract}

\section{INTRODUCTION}

Streptococcus mutans, known to be a major pathogen of dental caries, is classified into four serotypes (c, e, f and k) based on the chemical composition of the serotype-specific rhamnose glucose polymers (Hamada \& Slade, 1980; Nakano et al., 2004a). The distribution frequency of those serotypes among clinical oral isolates has been investigated, which showed that the majority, approximately $70-80 \%$, were classified as serotype c, followed by e (approx. $20 \%$ ), with less than $5 \%$ of the strains classified as serotype $\mathrm{f}$ or $\mathrm{k}$ (Hirasawa \& Takada, 2003; Shibata et al., 2003; Nakano et al., 2004b).

The GenBank/EMBL/DDBJ accession numbers for the $\mathrm{cnm}$ sequences of the 47 clinical isolates reported in this paper are AB465259AB465305.
The major cell surface protein antigens of $S$. mutans, which include three types of glucosyltransferases (Aoki et al., 1986; Pucci et al., 1987; Hanada \& Kuramitsu, 1989), a $190 \mathrm{kDa}$ protein antigen (PA) (Okahashi et al., 1989) and four types of glucan-binding proteins (Gbps) (Banas et al., 1997; Mattos-Graner et al., 2001; Sato et al., 1997; Shah \& Russell, 2004), have been widely investigated in studies related to its virulence for dental caries. Recently, the $120 \mathrm{kDa} \mathrm{Cnm}$ protein encoding the collagen-binding adhesin of $S$. mutans was characterized, and its encoding gene was cloned and sequenced (Sato et al., 2004). The distribution frequency of the $\mathrm{cnm}$ gene in $102 \mathrm{~S}$. mutans strains in our previous study was shown to be $21.4 \%$, with cnm-positive strains showing a predominant distribution among strains with the minor serotypes $f$ and $k$, which 
Table 1. PCR primers used in this study

\begin{tabular}{|c|c|c|c|}
\hline Name & Purpose & Sequence $\left(5^{\prime} \rightarrow 3^{\prime}\right)$ & Reference \\
\hline MKD-F & S. mutans detection & GGC ACC ACA ACA TTG GGA AGC TCA GTT & Hoshino et al. (2004) \\
\hline MKD-R & & GGA ATG CCG ATC AGT CAA CAG GAT & \\
\hline SC-F & Serotype c determination & CGG AGT GCT TTT TAC AAG TGC TGG & Shibata et al. (2003) \\
\hline SC-R & & AAC CAC GGC CAG CAA ACC CTT TAT & \\
\hline SE-F & Serotype e determination & CCT GCT TTT CAA GTA CCT TTC GCC & Shibata et al. (2003) \\
\hline SE-R & & CTG CTT GCC AAG CCC TAC TAG AAA & \\
\hline SF-F & Serotype f determination & CCC ACA ATT GGC TTC AAG AGG AGA & Shibata et al. (2003) \\
\hline SF-R & & TGC GAA ACC ATA AGC ATA GCG AGG & \\
\hline CEFK-F & Serotype $\mathrm{k}$ determination & ATT CCC GCC GTT GGA CCA TTC C & Nakano et al. (2004b) \\
\hline K-R & & CCA ATG TGA TTC ATC CCA TAC C & \\
\hline $\mathrm{cnm}-1 \mathrm{~F}$ & cnm amplification & GAC AAA GAA ATG AAA GAT GT & This study \\
\hline $\mathrm{cnm}-\mathrm{BF}$ & & GAC AAT CCT GAT CAA AAG AC & \\
\hline $\mathrm{cnm}-1 \mathrm{R}$ & & GCA AAG ACT CTT GTC CCT GC & \\
\hline cnm-IN1 & cnm sequencing & CTT GCA GAA TAT CAC CGG CTG G & This study \\
\hline cnm-IN2 & & GTG AGT CTT ATC GCG GTC AAG AAG G & \\
\hline $\mathrm{cnm}-\mathrm{CF}$ & RT-PCR for $\mathrm{cnm}$ & CTG AGG TTA CTG TCG TTA AA & This study \\
\hline $\mathrm{cnm}-\mathrm{CR}$ & & CAC TGT CTA CAT AAG CAT TC & \\
\hline
\end{tabular}

were also demonstrated to have unique features (Nakano et al., 2007).

The development of dental caries results in the destruction of enamel on tooth surfaces, leading to dentin exposure (Selwitz et al., 2007). The Cnm protein has been shown to possess binding activity to type I collagen (Sato et al., 2004), a major organic component of dentin, while approximately $20 \%$ of $S$. mutans strains studied were also shown to possess collagen-binding activity, which is regarded as an advantage for binding to exposed dentin (Switalski et al., 1993). In the present study, the distribution of strains with the $\mathrm{cnm}$ gene was analysed using saliva specimens from children and their mothers. Furthermore, we investigated the correlation between subjects with $\mathrm{cnm}$ positive strains and clinical parameters for dental caries.

\section{METHODS}

Bacterial strains. From 2002 to 2006, we isolated 213 oral strains of S. mutans from samples collected from 213 Japanese children who came to our clinic and 60 strains from 60 of their mothers who participated in oral hygiene lectures held at our clinic. In addition, 95 strains isolated from Japanese children who visited our clinic between 1982 and 1990, and 110 strains isolated in Finland in the early 1990s were investigated. All strains were confirmed to be $S$. mutans based on biochemical properties, such as positive sugar fermentation profiles for mannitol, sorbitol, raffinose and melibiose ( $1 \%$ each) in phenol red broth (Difco), and a rough colony morphology on Mitis Salivarius agar (Difco) plates containing bacitracin $\left(0.2 \mathrm{U} \mathrm{ml}^{-1}\right.$; Sigma Chemical) and $15 \%(\mathrm{w} / \mathrm{v})$ sucrose. Furthermore, confirmation of $S$. mutans and serotype determination were carried out by PCR using $S$. mutans-specific and serotype-specific sets of primers, which are listed in Table 1.

Determination of $\mathbf{c n m}$ sequence. The entire length of the $\mathrm{cnm}$ gene in all of the strains was amplified by PCR using TaKaRa Ex Taq polymerase (Takara Bio) with appropriate primers ( $\mathrm{cnm}-1 \mathrm{~F}$ and cnm-1R; Table 1, Fig. 1), which were constructed based on the $\mathrm{cnm}$ nucleotide alignment of strain $\mathrm{Z} 1$ in the GenBank database (GenBank accession no. AB102689). PCR amplification was performed in a thermal cycler (iCycler; Bio-Rad) with the following cycling parameters: initial denaturation at $95{ }^{\circ} \mathrm{C}$ for $4 \mathrm{~min}$, and then 30 cycles consisting $95{ }^{\circ} \mathrm{C}$ for $30 \mathrm{~s}, 60{ }^{\circ} \mathrm{C}$ for $30 \mathrm{~s}$ and $72{ }^{\circ} \mathrm{C}$ for $2 \mathrm{~min}$, with a final extension at $72{ }^{\circ} \mathrm{C}$ for $7 \mathrm{~min}$. The amplified fragments

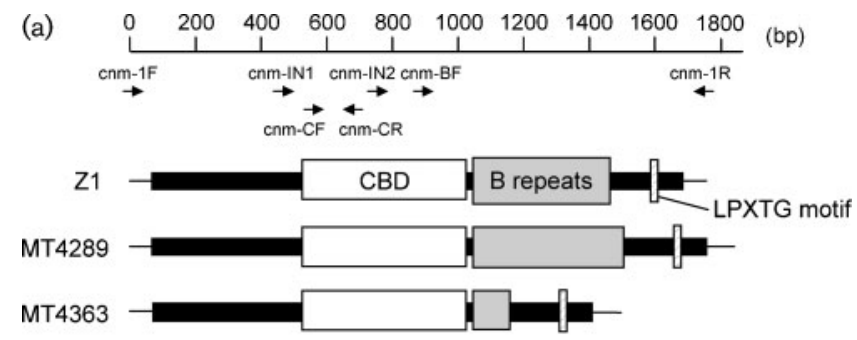

(b)

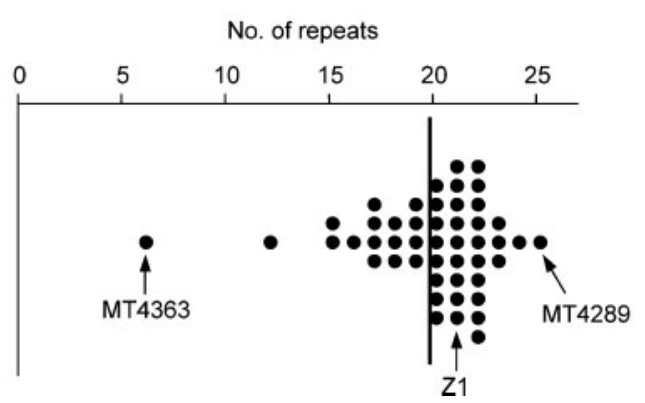

Fig. 1. Proposed structure of $\mathrm{Cnm}$ in S. mutans clinical isolates. (a) The putative structure of $\mathrm{Cnm}$ in representative strains (MT4289 and MT4363) in comparison to that in strain Z1 is illustrated. Horizontal lines indicate the entire length of the $\mathrm{cnm}$ gene. Arrows indicate the primer positions, designed based on the nucleotide alignment of the $\mathrm{cnm}$ gene of strain Z1. Filled rectangles show the ORFs. CBD, Collagen-binding domain. (b) Number of repeats in the $B$ repeats region for 47 clinical isolates. The bold vertical bar indicates the mean value. 
from 47 strains were cloned into a pGEM-T Easy vector (Promega) and their nucleotide alignments were determined using a dyeterminator reaction with a DNA sequencing system (ABI Prism 310 genetic analyser; Applied Biosystems) and a BigDye terminator cycle sequencing kit. In order to obtain the complete sequence, internal primers (cnm-IN1 and cnm-IN2; Table 1, Fig. 1) were utilized. Data analysis was performed with Gene Works software (IntelliGenetics). The sequences of each strain were compared using multiple alignment analysis with CLUSTAL w from the DNA Data Bank of Japan (DDBJ; Mishima, Japan) (Thompson et al., 1994).

mRNA expression of the Cnm-encoding gene. To confirm mRNA expression of the collagen-binding domain of the $\mathrm{cnm}$ gene, an RT-PCR method was used with $\mathrm{cnm}-\mathrm{CF}$ and $\mathrm{cnm}-\mathrm{CR}$ primers (Table 1), as described previously (Nomura et al., 2005). In order to confirm that cDNA was successfully extracted, amplification of $16 \mathrm{~S}$ rRNA was performed using the following sets of primers: $5^{\prime}$-GTG GGA CGC AAG GAA ACA CAC TGT GC-3' and 5'-CGT CGC CTT GGT AAG CTC TTA CCT TAC C-3' (Matsumoto-Nakano \& Kuramitsu, 2006).

Collagen-binding properties of clinical strains. Collagen-binding properties were evaluated according to the method described by Waterhouse \& Russell (2006), with some modifications. Type I collagen [collagen (type I) in $0.25 \mathrm{M}$ acetic acid; Sigma] was coated onto 96-well tissue culture plates (Beckton Dickinson) and incubated overnight at $4{ }^{\circ} \mathrm{C}$, then the plates were washed three times with PBS and blocked for $1.5 \mathrm{~h}$ with $5 \%$ BSA in PBS at $37{ }^{\circ} \mathrm{C}$. Next, the wells were washed again with PBS containing $0.01 \%$ Tween 20. Cells from overnight cultures of $S$. mutans grown in brain heart infusion broth (Difco) were collected by centrifugation and added to the wells, after the bacterial numbers were adjusted with PBS. After $3 \mathrm{~h}$ incubation at $37^{\circ} \mathrm{C}$, adherent cells were washed three times with PBS, then fixed with $200 \mu \mathrm{l} 25 \%$ formaldehyde at room temperature for $30 \mathrm{~min}$. After another three washes with PBS, the adherent cells were stained with $200 \mu \mathrm{l} 0.05 \%$ crystal violet (Wako) in water for $1 \mathrm{~min}$ and washed three times with PBS, then the dye was dissolved by adding $7 \%$ acetic acid $(200 \mu \mathrm{l})$ before determining the $A_{595}$. First, the correlations of the amount of collagen $(0.002-2 \mathrm{mg})$ and the number of bacteria $\left(1 \times 10^{8}-1 \times 10^{10}\right.$ c.f.u. $)$ with the collagen-binding activities of the TW871 (cnm-positive) and MT8148 (cnm-negative) strains were evaluated. Then, the collagen-binding activities of 99 clinical strains (47 cnm-positive and $52 \mathrm{cnm}$-negative strains) were analysed under the fixed condition of $2 \mathrm{mg}$ collagen and $1 \times 10^{10}$ bacterial cells. The results for each strain were expressed as a percentage as compared to the binding property of TW871, which was defined as $100 \%$.

PCR methods for identification of strains with the $\mathbf{c n m}$ gene. Based on the nucleotide alignment determined for the 47 strains, primer sets designed to specifically detect $\mathrm{cnm}$-positive strains were constructed (cnm-BF and cnm-1R; Table 1, Fig. 1). PCR amplification was performed using TaKaRa Ex Taq polymerase (Takara Bio) with the following cycling parameters: initial denaturation at $95{ }^{\circ} \mathrm{C}$ for $4 \mathrm{~min}$, and then 30 cycles consisting of $95{ }^{\circ} \mathrm{C}$ for $30 \mathrm{~s}, 60{ }^{\circ} \mathrm{C}$ for $30 \mathrm{~s}$ and $72{ }^{\circ} \mathrm{C}$ for $1 \mathrm{~min}$, with a final extension at $72{ }^{\circ} \mathrm{C}$ for $7 \mathrm{~min}$. First, the specificity of our method was confirmed using 102 strains in which the presence of the $\mathrm{cnm}$ gene had been confirmed by Southern blot hybridization in our previous study (Nakano et al., 2007). In addition, PCR analysis was carried out for all bacterial strains used in this study whose complete sequence had been determined, with those results also used to confirm specificity. Finally, the sensitivity of the method was determined using titrated cultures of $S$. mutans NN2115 (serotype f). When analysed using simultaneous PCR assays with known numbers of bacterial cells diluted in sterile distilled water, the detection limit of our method was revealed to range from 10 to 100 cells.
Detection of S. mutans with the cnm gene in saliva specimens from children and their mothers. All of the procedures in the present study were approved by the Ethical Committee of the Osaka University Graduate School of Dentistry. Expectorated whole saliva specimens were collected from 101 mother-child pairs (mothers, 24-47 years of age; children, 47 boys and 54 girls, $2-15$ years old) who participated in oral hygiene lectures at our clinic from 2005 to 2007. The specimens were processed for the PCR assay using a method reported previously (Hoshino et al., 2004). PCR analyses were performed to determine the presence of $S$. mutans DNA and the $\mathrm{cnm}$ gene using the method described in the section above.

Correlation of the presence of S. mutans species with the cnm gene and dental caries. In order to compare the incidence of dental caries in primary teeth, 48 children who came to our clinic from 2005 to 2007 ( 22 boys and 26 girls, 3-8 years of age) were selected based on the following criteria: precise clinical records were available regarding dental caries when the saliva specimens were taken, and the subject possessed more than 14 primary teeth and less than 8 permanent teeth, which corresponded to children under the age of 8 . Clinical examinations were carried out with a mirror and explorer under a dental operation light by a single skilled examiner according to criteria established by the WHO (1987). The subjects were divided into three groups: those with $\mathrm{cnm}$-positive $S$. mutans (group A), those with $\mathrm{cnm}$-negative $S$. mutans (group B) and those without $S$. mutans detected (group C). The condition of the primary teeth was expressed as numbers of teeth that were decayed (d), extracted due to dental caries (e) and had filled surfaces (f) (defs). The results are expressed as the 'defs rate', which was calculated by dividing $(\mathrm{d}+\mathrm{e}+\mathrm{f})$ by the total number of surfaces (s).

Statistical analyses. Statistical analyses were carried out using the computational software packages StatView 5.0 (SAS Institute) and Prism 4 (GraphPad Software). Collagen-binding activities of the $\mathrm{cnm}$ positive and $\mathrm{cnm}$-negative strains were compared using Student's $t$ test. Fisher's protected least-significant difference test was used to compare detection rates of $S$. mutans with the $\mathrm{cnm}$ gene in children whose mothers possessed cnm-positive $S$. mutans as compared to children whose mothers did not. The relationship between the intensity of the mRNA expression of the $\mathrm{cnm}$ gene and collagenbinding properties was analysed using regression analysis. The values for the odds ratio and $95 \%$ confidence interval were calculated to determine the significance of the association between children with $S$. mutans with the $\mathrm{cnm}$ gene and their mothers possessing the same. Comparisons among scores for dental caries in subjects possessing $\mathrm{cnm}$-positive S. mutans, those possessing $\mathrm{cnm}$-negative S. mutans, and those without $S$. mutans were performed using one-way ANOVA (Bonferroni multiple comparison test). $P$ values less than 0.05 were considered to be significant.

\section{RESULTS AND DISCUSSION}

\section{Prevalence of $\mathbf{c n m}$-positive S. mutans clinical isolates}

A total of 47 of the 478 tested strains were shown to possess the $\mathrm{cnm}$ gene, thus the prevalence of $S$. mutans with $\mathrm{cnm}$ among oral isolates was $9.8 \%$. Table 2 lists the prevalence of cnm-positive strains based on serotype classification. The rate of detection for the $\mathrm{cnm}$ gene in serotype $\mathrm{f}$ strains was the highest, followed by serotype $\mathrm{k}$, while 25 of 359 serotype c strains were found to be positive. A comparison of frequencies in Japanese children in different decades showed that strains isolated in 2002-2006 had a significantly lower 
Table 2. Prevalence of $\mathrm{cnm}$ gene in $S$. mutans oral isolates from various populations

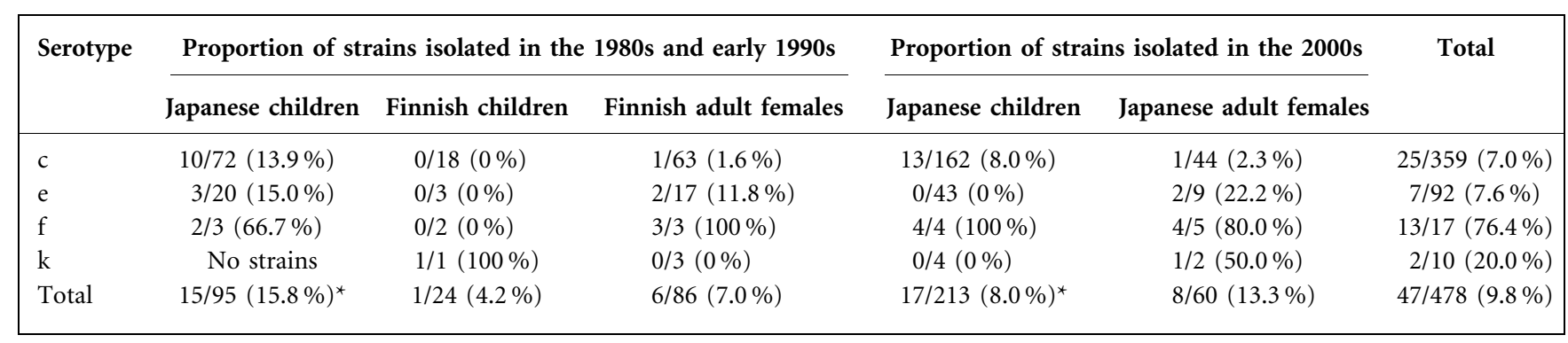

${ }^{\star} P<0.05$ between the two groups by Fisher's exact probability test.

detection rate $(8.0 \%)$ than those isolated in $1982-1990$ (15.8\%, $P<0.05)$. Furthermore, the detection rate in samples collected from Japanese adult females in 20022006 was shown to be $13.3 \%$, which was higher than that in those from children in 2002-2006, though the difference was not statistically significant. This finding may indicate that the cnm gene is acquired with age, while another possibility is that the dental health of the mothers in their childhood was not as good as that of their children. As for Finnish subjects, there were only seven strains isolated in the early 1990s found to be positive for the $\mathrm{cnm}$ gene and the detection rate was lower than that of strains from Japanese children isolated in the period from 1982-1990, indicating that the prevalence of $\mathrm{cnm}$-positive strains might be geographically dependent, though the difference was not statistically significant.

\section{Molecular characterization of $\mathbf{c n m}$ in S. mutans clinical isolates}

Fig. 1(a) shows an illustration of the presumed Cnm protein structure in the clinical isolates analysed in the present study. The putative amino acid sequence of the cnm gene of strain Z1 (GenBank accession no. AB102689) was reported to contain 538 amino acids, which includes the collagen-binding domain (CBD; residues 152-316), putative B repeats domain (residues 328-455) and an LPXTG motif (residues 507-511) (Sato et al., 2004). This is the first study to perform molecular analyses of the $\mathrm{cnm}$ gene using a large number of $S$. mutans clinical isolates. Our analysis of the nucleotide alignment of $\mathrm{cnm}$ in 47 clinical isolates showed that the number of amino acids ranged from 448 (strain MT4363) to 564 (strain MT4289). The amino acid sequence of the CBD in all of the strains was nearly the same and the LPXTG motif was confirmed to be conserved among all. As for the number of $B$ repeats, strain $\mathrm{Z} 1$ was reported to contain 21 repeats (Sato et al., 2004), whereas the numbers in the species analysed in the present study varied from 6 (strain MT4363) to 25 (strain MT4289), with the mean number for all 47 clinical strains shown to be 19.7, and most strains contained 15-25 repeats (Fig. 1b). The number of repeats and the length of the repeating units were shown to be dependent on species variation (Sato et al., 2004), thus we speculated that the $\mathrm{cnm}$ gene in S. mutans is exogenous and derived from multiple species. In addition, RT-PCR analysis revealed that the mRNA expression of the $\mathrm{cnm}$ gene was extremely weak in 11 of the 47 strains, half of which were isolated from Japanese children in the 1980s to early 1990s.

\section{Collagen-binding properties of clinical strains}

A number of studies have noted the cellular adhesion of $S$. mutans to collagen, and strains with and without collagenbinding properties have been reported (Love et al., 1997; Petersen et al., 2002). Recently, the Cnm protein was shown to possess collagen-binding activity (Sato et al., 2004) and its distribution frequency was reported to be approximately $20 \%$ (Nakano et al., 2007), which is quite similar to that shown for S. mutans strains with collagenbinding properties (Switalski et al., 1993). Thus, the collagen-binding properties of $S$. mutans was investigated in the present study by focusing on the Cnm protein.

The collagen-binding properties of TW871 were shown to increase with corresponding increases in the amounts of collagen and bacteria (Fig. 2a, b), while strain MT8148 showed no collagen-binding properties. Furthermore, the assay with 99 clinical strains using $2 \mathrm{mg}$ collagen and $10^{10}$ bacterial cells showed that the collagen-binding properties of strains with the $\mathrm{cnm}$ gene were significantly higher than those of strains without the gene $(P<0.01)$ (Fig. 2c). With the properties of TW871 defined as $100 \%$, the binding intensity of the strains with the $\mathrm{cnm}$ gene ranged from 0.0 to $217.9 \%$. Approximately half of the strains had high binding properties, for $20 \%$ strains though the binding properties were extremely weak. RT-PCR results for the strains with extremely weak binding showed that the mRNA expression of the $\mathrm{cnm}$ gene in those was also extremely weak. In addition, $\mathrm{cnm}$ mRNA expression was positively correlated with the intensity of collagen binding (regression analysis $P=0.0109, r=0.37)$. Based on these results, it is reasonable to speculate that the Cnm protein is one of the major factors associated with the collagen-binding properties of S. mutans. However, it should be noted that 11 strains (1 serotype e, 3 serotype $\mathrm{f}$ and 7 serotype $\mathrm{k}$ ) without the $\mathrm{cnm}$ gene had collagen-binding properties, indicating the involvement of other unknown crucial factors in these strains. 
(a)

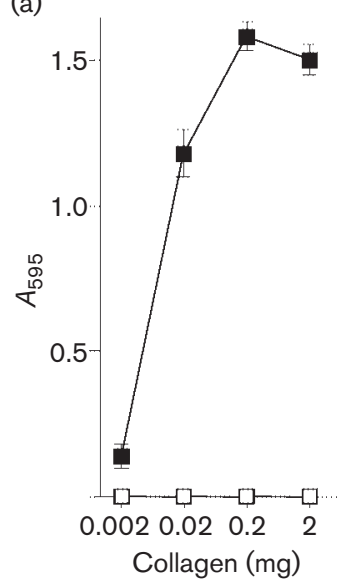

(b)

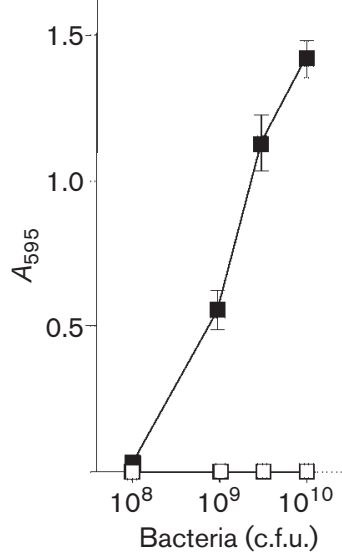

(c)

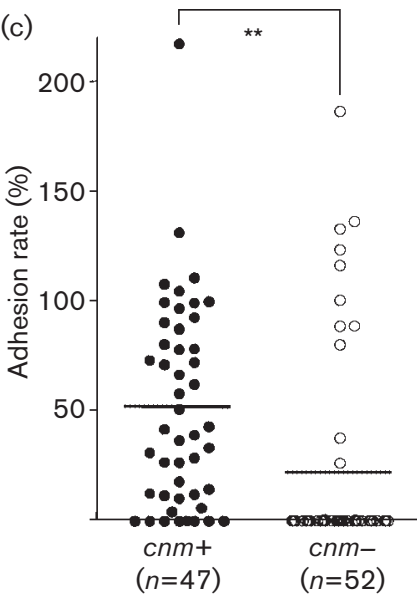

Fig. 2. Collagen-binding properties of $S$. mutans cells. (a) S. mutans MT8148 and TW871 cells $\left(1 \times 10^{10}\right.$ c.f.u. $)$ were added separately to wells coated with various amounts of collagen. (b) Various amounts of S. mutans MT8148 and TW871 cells $\left(1 \times 10^{8}-1 \times 10^{10}\right.$ c.f.u. $)$ were added separately to wells coated with $2 \mathrm{mg}$ collagen. (c) S. mutans strains $\left(1 \times 10^{10} \mathrm{c}\right.$.f.u. $)$ with or without the $\mathrm{cnm}$ gene were added to plates coated with $2 \mathrm{mg}$ collagen. Statistically significant differences were found between the two groups (Student's $t$-test ${ }^{* *} P<0.01$ ). Horizontal bars indicate the mean values. $\square$, MT8148: $\mathbf{\square}$, TW871; $\bigcirc, \mathrm{cnm}$ negative strain; $\bullet$, cnm-positive strain. The collagen binding of TW871 was defined as $100 \%$.

\section{Vertical transmission of S. mutans with $\mathrm{cnm}$ analysed using saliva specimens}

Interfamilial transmission of $S$. mutans has been widely investigated using serotype classification (Berkowitz et al., 1975), bacteriocin activity profiles (Davey \& Rogers, 1984), chromosomal DNA fingerprinting (Emanuelsson \& Thornqvist, 2000), ribotyping (Köhler et al., 2003), an arbitrarily primed PCR method (Li \& Caufield, 1998) and multilocus sequence typing (Nakano et al., 2007), with the results of most of those indicating mother-to-child transmission. However, few investigations of mother-to-child transmission have focused on specific virulent genes. $\mathrm{Li}$ et al. (2005) analysed the transmitted and non-transmitted strains focusing on the genes encoding mutacin, which showed that the strains with mutAI were found frequently in the non-transmitted group. In the present study, we focused on the $\mathrm{cnm}$ gene in order to determine whether $S$. mutans strains with or without the gene were highly transmissible. Saliva specimens from 55 pairs of mothers and their children were positive for $S$. mutans, which were divided into 4 groups based on the absence or presence of the bacterium and the $\mathrm{cnm}$ gene (Fig. $3 \mathrm{a}$ ). The $\mathrm{cnm}$ gene was detected in $32.7 \%$ of the $S$. mutans-positive children
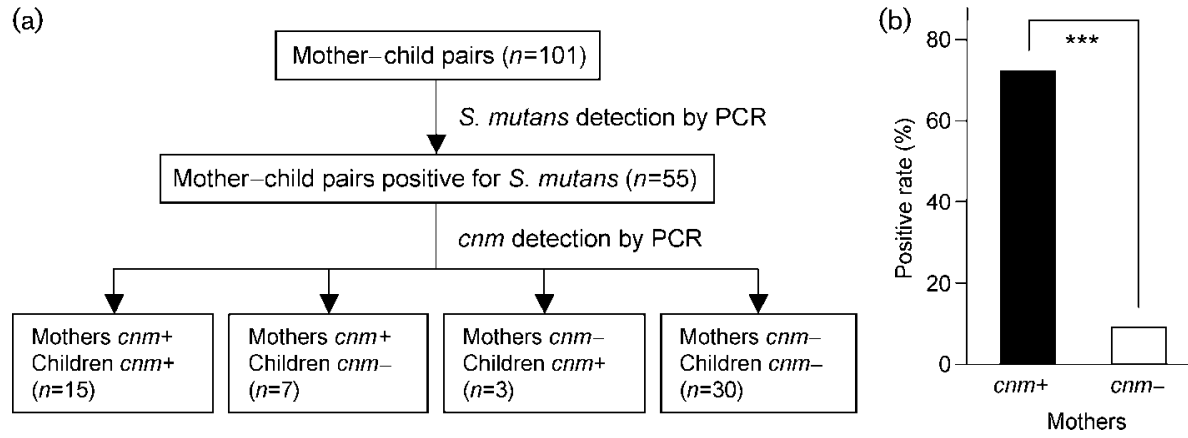

Fig. 3. Detection of $S$. mutans with the $\mathrm{cnm}$ gene in saliva specimens from mother-child pairs. (a) The occurrence of strains with the $\mathrm{cnm}$ gene was analysed in children, and the subjects were categorized into those with mothers who did or did not possess $\mathrm{cnm}$-positive strains. A total of 55 mother-child pairs shown to harbour $S$. mutans in saliva specimens were classified into four categories based on identification of the $\mathrm{cnm}$ gene in the bacteria found in the children and their mothers. (b) Detection rates of the $\mathrm{cnm}$ gene in children categorized as those with mothers who did or did not possess strains with the $\mathrm{cnm}$ gene. Statistically significant differences were found between the two groups (Fisher's protected least-significant difference test $\left.{ }^{\star * \star} P<0.0001\right)$. 
(a)

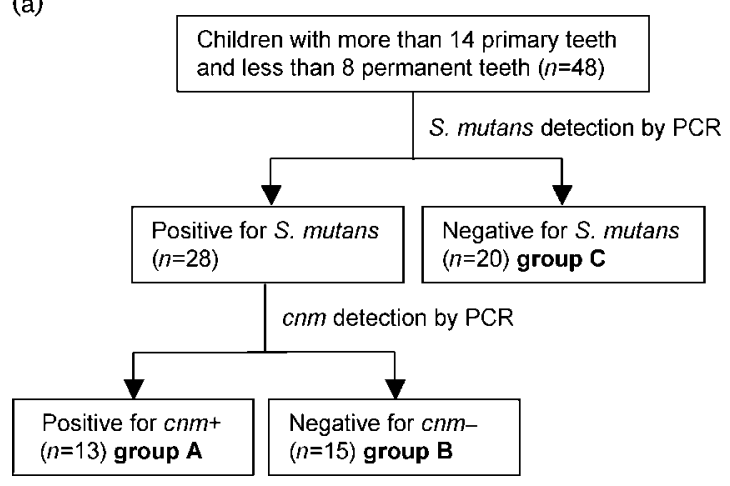

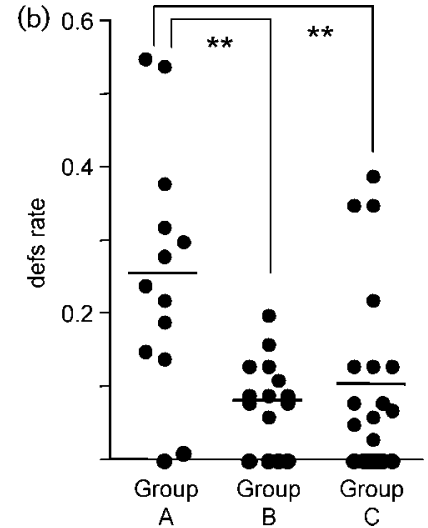

Fig. 4. Correlation of dental caries status and identification of $S$. mutans with or without the cnm gene. (a) Child subjects categorized by the presence of $S$. mutans and the $\mathrm{cnm}$ gene. Forty-eight children were divided into $S$. mutans-positive and -negative groups, with the $S$. mutans-positive group further classified as cnm-positive or -negative. (b) Scores for dental caries subjects based on the classification in (a). Statistically significant differences were found among the groups (Bonferroni multiple comparison test ${ }^{\star \star} P<0.01$ ).

and $40 \%$ of the S. mutans-positive mothers. Furthermore, the rate of children with $\mathrm{cnm}$-positive $S$. mutans whose mothers also possessed cnm-positive S. mutans was $72 \%$, which was significantly higher than that of those whose mothers did not $(9.1 \%)(P<0.0001$, odds ratio $17.5,95 \%$ confidence interval 1.2-250.4) (Fig. 3b). The rate of children with $\mathrm{cnm}$-positive $S$. mutans whose mothers also possessed $\mathrm{cnm}$-positive $S$. mutans was high, which indicates that vertical transmission occurred in the $\mathrm{cnm}$-positive mother-child pairs.

\section{Dental caries experience of children with cnm- positive saliva specimens}

Once dental caries progresses, demineralization of the tooth surface occurs and the dentin becomes exposed (Selwitz et al., 2007). It is reasonable to speculate that strains with collagen-binding properties have an advantage with respect to attaching to dentin, in which the main organic component is type I collagen. In this study, we focused on detection of strains with the $\mathrm{cnm}$ gene encoding collagenbinding adhesin in order to consider the clinical association between the presence of strains with the $\mathrm{cnm}$ gene and dental caries. It has been reported that multiple genotypes of $S$. mutans are present in the oral cavity (Grönroos \& Alaluusua, 2000; Kozai et al., 1999; Saarela et al., 1996). Thus, saliva specimens, which carry microbes representative of the whole oral cavity, were considered appropriate for the identification of $\mathrm{cnm}$-positive $S$. mutans in the oral cavity as compared to analyses of isolated strains. In addition, saliva specimen analysis requires much less time than isolation of strains and extraction of their genomic DNA.

Forty-eight children were selected based on the availability of precise clinical records regarding their dental caries and number of teeth emerged in the oral cavity (more than 14 primary teeth and less than 8 permanent teeth). A total of 28 were positive for $S$. mutans, of whom 13 possessed $\mathrm{cnm}$ positive S. mutans (group A) and 15 did not (group B) (Fig. 4a). As for children with S. mutans either positive or negative for $\mathrm{cnm}$, those in group A had a significantly higher defs rate than those in group $\mathrm{B}(P<0.01)$ (Fig. $4 \mathrm{~b})$. In addition, children without $S$. mutans detected (group C) had a significantly lower defs rate as compared to group A $(P<0.01)$, whereas there was no significant difference between groups $\mathrm{B}$ and $\mathrm{C}$. This finding implies that the presence of the $\mathrm{Cnm}$ protein of $S$. mutans is closely correlated with experiencing dental caries. On the other hand, there were several subjects positive for $S$. mutans with $\mathrm{cnm}$ who had low caries scores, which indicates that other factors also play important roles in the development of dental caries. Taken together, our results suggest that individuals with $\mathrm{cnm}$-positive $S$. mutans are at possible risk for the development of dental caries.

\section{ACKNOWLEDGEMENTS}

This study was supported by the 21st Century Center of Excellence (COE) programme entitled 'Origination of Frontier BioDentistry' at Osaka University Graduate School of Dentistry supported by the Ministry of Education, Culture, Sports, Science and Technology of Japan, Grants-in-Aid for Scientific Research (A) 19209063 and (B) 16390605, Grants-in-Aid for Exploratory Research 17659647 and 19659538 from Japan Society for Promotion of Science, and Grants-in-Aid for Young Scientists (A) 18689050 and (B) 19791572 from the Ministry of Education, Culture, Sports, Science and Technology of Japan.

\section{REFERENCES}

Aoki, H., Shiroza, T., Hayakawa, M., Sato, S. \& Kuramitsu, H. K. (1986). Cloning of a Streptococcus mutans glucosyltransferase gene coding for insoluble glucan synthesis. Infect Immun 53, 587-594. 
Banas, J. A., Potvin, H. C. \& Singh, R. N. (1997). The regulation of Streptococcus mutans glucan-binding protein A expression. FEMS Microbiol Lett 154, 289-292.

Berkowitz, R. J., Jordan, H. V. \& White, G. (1975). The early establishment of Streptococcus mutans in the mouths of infants. Arch Oral Biol 20, 171-174.

Davey, A. L. \& Rogers, A. H. (1984). Multiple types of the bacterium Streptococcus mutans in the human mouth and their intra-family transmission. Arch Oral Biol 29, 453-460.

Emanuelsson, I. R. \& Thornqvist, E. (2000). Genotypes of mutans streptococci tend to persist in their host for several years. Caries Res 34, 133-139.

Grönroos, L. \& Alaluusua, S. (2000). Site-specific oral colonization of mutans streptococci detected by arbitrarily primed PCR fingerprinting. Caries Res 34, 474-480.

Hamada, S. \& Slade, H. D. (1980). Biology, immunology, and cariogenicity of Streptococcus mutans. Microbiol Rev 44, 331-384.

Hanada, N. \& Kuramitsu, H. K. (1989). Isolation and characterization of the Streptococcus mutans gtfD gene, coding for primer-dependent soluble glucan synthesis. Infect Immun 57, 2079-2085.

Hirasawa, M. \& Takada, K. (2003). A new selective medium for Streptococcus mutans and the distribution of S. mutans and S. sobrinus and their serotypes in dental plaque. Caries Res 37, 212-217.

Hoshino, T., Kawaguchi, M., Shimizu, N., Hoshino, N., Ooshima, T. \& Fujiwara, T. (2004). PCR detection and identification of oral streptococci in saliva samples using gtf genes. Diagn Microbiol Infect Dis 48, 195-199.

Köhler, B., Lundberg, A. B., Birkhed, D. \& Papapanou, P. N. (2003). Longitudinal study of intrafamilial mutans streptococci ribotypes. Eur J Oral Sci 111, 383-389.

Kozai, K., Nakayama, R., Tedjosasongko, U., Kuwahara, S., Suzuki, J., Okada, M. \& Nagasaka, N. (1999). Intrafamilial distribution of mutans streptococci in Japanese families and possibility of father-tochild transmission. Microbiol Immunol 43, 99-106.

Li, Y. \& Caufield, P. W. (1998). Arbitrarily primed polymerase chain reaction fingerprinting for the genotypic identification of mutans streptococci from humans. Oral Microbiol Immunol 13, 17-22.

Li, S., Liu, T., Xiao, X., Yang, J., Yang, D., Zhuang, H. \& Liu, Z. (2005). Detection of mutA genes in transmitted strains and nontransmitted strains of mutans streptococci. Caries Res 39, 417-421.

Love, R. M., McMillan, M. D. \& Jenkinson, H. F. (1997). Invasion of dentinal tubules by oral streptococci is associated with collagen recognition mediated by the antigen I/II family of polypeptides. Infect Immun 65, 5157-5164.

Matsumoto-Nakano, M. \& Kuramitsu, H. K. (2006). Role of bacteriocin immunity proteins in the antimicrobial sensitivity of Streptococcus mutans. J Bacteriol 188, 8095-8102.

Mattos-Graner, R. O., Jin, S., King, W. F., Chen, T., Smith, D. J. \& Duncan, M. J. (2001). Cloning of the Streptococcus mutans gene encoding glucan binding protein $\mathrm{B}$ and analysis of genetic diversity and protein production in clinical isolates. Infect Immun 69, 6931-6941.

Nakano, K., Nomura, R., Nakagawa, I., Hamada, S. \& Ooshima, T. (2004a). Demonstration of Streptococcus mutans with a cell wall polysaccharide specific to a new serotype, $k$, in the human oral cavity. J Clin Microbiol 42, 198-202.

Nakano, K., Nomura, R., Shimizu, N., Nakagawa, I., Hamada, S. \& Ooshima, T. (2004b). Development of a PCR method for rapid identification of new Streptococcus mutans serotype $k$ strains. J Clin Microbiol 42, 4925-4930.

Nakano, K., Lapirattanakul, J., Nomura, R., Nemoto, H., Alaluusua, S., Grönroos, L., Vaara, M., Hamada, S., Ooshima, T. \& Nakagawa, I. (2007). Streptococcus mutans clonal variation revealed by multilocus sequence typing. J Clin Microbiol 45, 2616-2625.

Nomura, R., Nakano, K. \& Ooshima, T. (2005). Molecular analysis of the genes involved in the biosynthesis of serotype specific polysaccharide in the novel serotype $k$ strains of Streptococcus mutans. Oral Microbiol Immunol 20, 303-309.

Okahashi, N., Sasakawa, C., Yoshikawa, M., Hamada, S. \& Koga, T. (1989). Molecular characterization of a surface protein antigen gene from serotype c Streptococcus mutans, implicated in dental caries. Mol Microbiol 3, 673-678.

Petersen, F. C., Assev, A., van der Mei, H. C., Busscher, H. J. \& Scheie, A. A. (2002). Functional variation of the antigen I/II surface protein in Streptococcus mutans and Streptococcus intermedius. Infect Immun 70, 249-256.

Pucci, M. J., Jones, K. R., Kuramitsu, H. K. \& Macrina, F. L. (1987). Molecular cloning and characterization of the glucosyltransferase $\mathrm{C}$ gene $(g t f C)$ from Streptococcus mutans LM7. Infect Immun 55, 2176-2182.

Saarela, M., Hannula, J., Mättö, J., Asikainen, S. \& Alaluusua, S. (1996). Typing of mutans streptococci by arbitrarily primed polymerase chain reaction. Arch Oral Biol 41, 821-826.

Sato, Y., Yamamoto, Y. \& Kizaki, H. (1997). Cloning and sequence analysis of the $g b p C$ gene encoding a novel glucan-binding protein of Streptococcus mutans. Infect Immun 65, 668-675.

Sato, Y., Okamoto, K., Kagami, A., Yamamoto, Y., Igarashi, T. \& Kizaki, H. (2004). Streptococcus mutans strains harboring collagenbinding adhesion. J Dent Res 83, 534-539.

Selwitz, R. H., Ismail, A. I. \& Pitts, N. B. (2007). Dental caries. Lancet 369, 51-59.

Shah, D. S. \& Russell, R. R. (2004). A novel glucan-binding protein with lipase activity from the oral pathogen Streptococcus mutans. Microbiology 150, 1947-1956.

Shibata, Y., Ozaki, K., Seki, M., Kawato, T., Tanaka, H., Nakano, Y. \& Yamashita, Y. (2003). Analysis of loci required for determination of serotype antigenicity in Streptococcus mutans and its clinical utilization. J Clin Microbiol 41, 4107-4112.

Switalski, L. M., Butcher, W. G., Caufield, P. C. \& Lantz, M. S. (1993). Collagen mediates adhesion of Streptococcus mutans to human dentin. Infect Immun 61, 4119-4125.

Thompson, J. D., Higgins, D. G. \& Gibson, T. J. (1994). CLUSTAL W: improving the sensitivity of progressive multiple sequence alignment through sequence weighting, position-specific gap penalties and weight matrix choice. Nucleic Acids Res 22, 4673-4680.

Waterhouse, J. C. \& Russell, R. R. (2006). Dispensable genes and foreign DNA in Streptococcus mutans. Microbiology 152, 1777-1788.

WHO (1987). Oral Health Surveys: Basic Methods, 3rd edn. Geneva: World Health Organization. 